Tai Xi-Shi*, Jiang Guan-Yu, Yu Ya-Ting, Yao Hui and Wang Ai-Jing

\title{
Bis(ethanol-kO)-bis(6-aminopicolinato- $\left.\mathrm{k}^{2} \mathrm{~N}, 0\right)$ magnesium(II), $\mathrm{C}_{16} \mathrm{H}_{22} \mathrm{O}_{6} \mathrm{~N}_{4} \mathrm{Mg}$
}

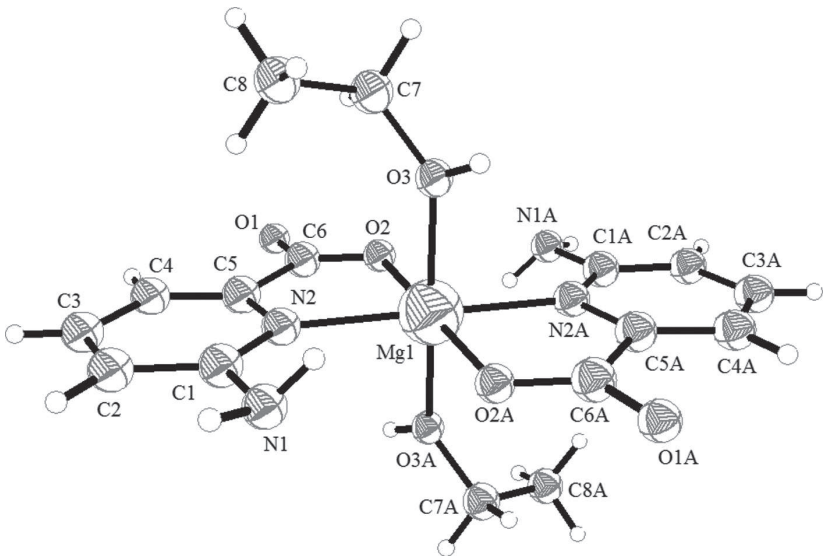

https://doi.org/10.1515/ncrs-2018-0345

Received September 11, 2018; accepted November 17, 2018; available online December 15, 2018

\begin{abstract}
$\mathrm{C}_{16} \mathrm{H}_{22} \mathrm{O}_{6} \mathrm{~N}_{4} \mathrm{Mg}$, triclinic, $P \overline{1} \quad$ (no. 2), $a=7.3165(15) \AA$, $b=8.2660(17) \AA, \quad c=8.7599(18) \AA, \quad \alpha=71.60(3)^{\circ}$, $\beta=77.07(3)^{\circ}, \quad \gamma=64.19(3)^{\circ}, \quad V=450.2(2) \AA^{3}, \quad Z=1$, $R_{\mathrm{gt}}(F)=0.0513, w R_{\text {ref }}\left(F^{2}\right)=0.1335, T=293(2) \mathrm{K}$.
\end{abstract}

\section{CCDC no.: 1879631}

The crystal structure is shown in the figure (ball-and-stick model with arbitrary atom radii; $\mathrm{A}=1-x, 1-y, 1-z)$. Tables 1 and 2 contain details on crystal structure and measurement conditions and a list of the atoms including atomic coordinates and displacement parameters.

\section{Source of materials}

In a typical experiment $0.138 \mathrm{~g}$ 2-amino-6-pyridinecarboxylic acid (1.0 mmol) and $0.04 \mathrm{~g}$ sodium hydroxide (1.0 mmol) were dissolved in a water-ethanol $(\mathrm{v}: \mathrm{v}=1: 5)$ solution at room temperature. After $0.5 \mathrm{~h}, 0.102 \mathrm{~g}$ magnesium chloride hexahydrate $(0.5 \mathrm{mmol})$ was added. The mixture was stirred for $6 \mathrm{~h}$ at $80^{\circ} \mathrm{C}$. Then the mixture was filtered. The colorless

\footnotetext{
*Corresponding author: Tai Xi-Shi, College of Chemistry and Chemical Engineering, Weifang University, Weifang, Shandong 261061, P.R. China, e-mail: taixs@wfu.edu.cn

Jiang Guan-Yu, Yu Ya-Ting, Yao Hui and Wang Ai-Jing: College of Chemistry and Chemical Engineering, Weifang University, Weifang, Shandong 261061, P.R. China
}

Table 1: Data collection and handling.

\begin{tabular}{ll}
\hline Crystal: & Colorless block \\
Size: & $0.19 \times 0.18 \times 0.17 \mathrm{~mm}$ \\
Wavelength: & Mo $K \alpha$ radiation $(0.71073 \AA)$ \\
$\mu:$ & $0.14 \mathrm{~mm}^{-1}$ \\
Diffractometer, scan mode: & Bruker SMART, $\omega$-scans \\
$\theta_{\text {max }}$, completeness: & $27.5^{\circ},>99 \%$ \\
$N(h k l)_{\text {measured }}, N(h k l)_{\text {unique }}, R_{\text {int }}:$ & $4447,2047,0.019$ \\
Criterion for $I_{\text {obs }}, N(h k l)_{\text {gt }}:$ & $I_{\text {obs }}>2 \sigma\left(I_{\text {obs }}\right), 1805$ \\
$N(\text { param })_{\text {refined }}:$ & 125 \\
Programs: & Bruker programs [1], OLEX2 [2], \\
& SHELX [3], DIAMOND [4] \\
\hline
\end{tabular}

Table 2: Fractional atomic coordinates and isotropic or equivalent isotropic displacement parameters $\left(\AA^{2}\right)$.

\begin{tabular}{lrrrr}
\hline Atom & $\boldsymbol{x}$ & $\boldsymbol{y}$ & $\boldsymbol{z}$ & $\boldsymbol{U}_{\text {iso }}{ }^{*} \boldsymbol{U}_{\text {eq }}$ \\
\hline Mg1 & 0.500000 & 0.500000 & 0.500000 & $0.0256(2)$ \\
O1 & $0.09343(15)$ & $0.41917(14)$ & $0.31504(13)$ & $0.0372(3)$ \\
O2 & $0.36464(14)$ & $0.37745(12)$ & $0.41958(12)$ & $0.0322(3)$ \\
O3 & $0.69891(14)$ & $0.51565(15)$ & $0.28361(11)$ & $0.0367(3)$ \\
H3 & 0.812541 & 0.509690 & 0.287946 & $0.055^{*}$ \\
N1 & $0.3349(2)$ & $0.97527(17)$ & $0.39545(17)$ & $0.0430(3)$ \\
H1A & 0.440559 & 0.893466 & 0.443003 & $0.052^{*}$ \\
H1B & 0.308162 & 1.091372 & 0.377754 & $0.052^{*}$ \\
N2 & $0.25541(15)$ & $0.73982(14)$ & $0.37737(12)$ & $0.0250(3)$ \\
C1 & $0.2110(2)$ & $0.92142(17)$ & $0.34861(15)$ & $0.0289(3)$ \\
C2 & $0.0398(2)$ & $1.05653(19)$ & $0.2672(2)$ & $0.0412(4)$ \\
H2 & 0.009695 & 1.182264 & 0.248516 & $0.049^{*}$ \\
C3 & $-0.0799(3)$ & $0.9995(2)$ & $0.2170(2)$ & $0.0515(5)$ \\
H3A & -0.193242 & 1.086805 & 0.163801 & $0.062^{*}$ \\
C4 & $-0.0338(2)$ & $0.8109(2)$ & $0.2446(2)$ & $0.0430(4)$ \\
H4 & -0.114496 & 0.770409 & 0.210392 & $0.052^{*}$ \\
C5 & $0.13439(18)$ & $0.68685(17)$ & $0.32384(15)$ & $0.0268(3)$ \\
C6 & $0.20005(19)$ & $0.47872(17)$ & $0.35537(15)$ & $0.0266(3)$ \\
C7 & $0.6765(3)$ & $0.5364(2)$ & $0.11994(19)$ & $0.0467(4)$ \\
H7A & 0.585357 & 0.479505 & 0.119538 & $0.056^{*}$ \\
H7B & 0.808387 & 0.469716 & 0.067907 & $0.056^{*}$ \\
C8 & $0.5958(3)$ & $0.7322(3)$ & $0.0235(2)$ & $0.0612(5)$ \\
H8A & 0.582721 & 0.735348 & -0.084169 & $0.092^{*}$ \\
H8B & 0.688026 & 0.788313 & 0.019020 & $0.092^{*}$ \\
H8C & 0.464569 & 0.799265 & 0.073285 & $0.092^{*}$ \\
\hline & & & &
\end{tabular}

crystals of title complex were obtained by slow evaporation in 7 days.

This work is licensed under the Creative Commons Attribution 4.0 Public 


\section{Experimental details}

The hydrogen atoms were positioned geometrically $(\mathrm{C}-\mathrm{H}=$ $0.93-0.97 \AA, \mathrm{O}-\mathrm{H}=0.82 \AA$ and $\mathrm{N}-\mathrm{H}=0.86 \AA$ ). Their $U_{\text {iso }}$ values were set to $1.2 U_{\text {eq }}$ or $1.5 U_{\text {eq }}$ of the parent atoms.

\section{Comment}

Metal complexes constructed by ligands containing carboxylic acid groups have received attention, which is not only because of their structural diversities, but also their potential applications, such as catalysis, bioactivity, luminescence and electrochemistry [5-8]. However, the above metal complexes are mainly focused in transition metal complexes. In order to enrich the content of coordination chemistry, we have been devoted to the synthesis and properties of alkalineearth metal complexes $[9,10]$. In this paper, we reported the structure of a new $\mathrm{Mg}$ (II) complex.

The asymmetric unit of the title crystal structure contais one half of the complex located on an inversion center ( $c f$. the figure). Bond lengths and angles in the aminopicolinato ligand are in agreement with the literature [11]. In the title complex, the central $\mathrm{Mg}$ (II) ion is six-coordinated with four $\mathrm{O}$ atoms from two aminopicolinato ligands ( $\mathrm{O} 2$ and $\mathrm{O} 2 \mathrm{~A})$ and two coordinated ethanol molecules ( 03 and $\mathrm{O} 3 \mathrm{~A}$ ), two $\mathrm{N}$ atoms from two aminopicolinato ligands (N2 and N2A), and forms a distorted octahedral coordination environment. The Mg-O bond distances are 2.0346(10) and 2.1219(12) Å, respectively, and the Mg-N bond distance is 2.1709(14). The complex forms a 1D polymeric structure by the interaction of $\mathrm{OH} \cdots \mathrm{O}$ hydrogen bonds.

Acknowledgements: This project was supported by the National Natural Science Foundation of China (no. 21171132), the Natural Science Foundation of Shandong (ZR2014BL003), the project of Shandong Province Higher Educational Science and Technology Program (J14LC01) and Science Foundation of Weifang.

\section{References}

1. Bruker. SAINT and SADABS. Bruker AXS Inc., Madison, WI, USA (2000).

2. Dolomanov, O. V.; Bourhis, L. J.; Gildea, R. J.; Howard, J. A. K.; Puschmann, H.: OLEX2: a complete structure solution, refinement and analysis program. J. Appl. Cryst. 42 (2009) 339-341.

3. Sheldrick, G. M.: Crystal structure refinement with SHELXL. Acta Crystallogr. C71 (2015) 3-8.

4. Brandenburg, K.: DIAMOND. Visual Crystal Structure Information System. Ver. 3.2. Crystal Impact, Bonn, Germany (2012).

5. Qin, G.-F.; Qin, Q.-Y.; Long, B.-F.; Wei, D.-P.; Xu, Y.-H.; Bao, S.-J.; Yin, X.-H.: Structural versatility and electrochemical properties of four copper(II) complexes based on $1 \mathrm{H}$ indazole-3-carboxylic acid. J. Iran. Chem. Soc. 14 (2017) $1227-1234$.

6. Tai, X.-S.; Guo, H.-M.; Guo, Q.-Q.: Synthesis, crystal structure and antitumor activity of a novel $\mathrm{Zn}$ (II) complex with 2-(nicotinoyloxy)acetic acid ligand. Chinese J. Struct. Chem. 37 (2018) 1052-1056.

7. Zhao, Q.; Ding, C.-H.; Feng, Y.-Q.: Structure, fluorescence, and carbon dioxide capture of a carboxylate cadmium complex. J. Coord. Chem. 71 (2018) 1250-1257.

8. Ferreirós-Martínez, R.; Esteban-Gómez, D.; Platas-Iglesias, C.; de Blas, A.; Rodríguez-Blas, T.: Zn(II), Cd(II) and Pb(II) complexation with pyridinecarboxylate containing ligands. Dalton Trans. (2008) 5754-5765.

9. Tai, X.-S.; Guo, Q.-Q.; Li, P.-F.; Liu, L.-L.: A Ca(II) coordination polymer of 2-carboxybenzaldehyde: Synthesis, crystal structure, and catalytic activity in oxidation of benzyl alcohol. Crystals 8 (2018) 150.

10. Tai, X.-S.; Zhang, Y.-P.; Zhao, W.-H.: Synthesis, crystal structure and antitumor activity of a dinuclear calcium complex based on 1,5-naphthalenedisulfonate and 2,2-bipyridine ligands. Res. Chem. Intermed. 41 (2015) 4339-4347.

11. Chin, J.; Chung, S.; Kim, D. H.: Synergistic effect between metal coordination and hydrogen bonding in phosphate and halide recognition. J. Am. Chem. Soc. 124 (2002) 10948-10949. 